\title{
PENGARUH BOKASHI TERHADAP PRODUKSI TERONG UNGU (Solanum melongena L.)
}

\author{
Ahmad Raksun ${ }^{1}$, I Gde Mertha ${ }^{1}$ \\ ${ }^{1}$ Dosen Program Studi Pendidikan Biologi FKIP Universitas Mataram \\ Email : ahmad.raksun@unram.ac.id
}

Diterima: 15 Maret 2018. Disetujui: 20 April 2018. Dipublikasikan: 14 Mei 2018

\begin{abstract}
Abstrak
Penelitian ini telah dilaksanakan di di Desa Montong are Kabupaten Lombok Barat. Penelitian ini bertujuan untuk mengetahui: (1) pengaruh pemberian bokashi terhadap produksi terong ungu, (2) kadar optimum bokashi yang harus diberikan pada lahan persawahan Desa Montong Are agar terong ungu dapat berprokduksi secara optimal. Dalam penelitian ini digunakan rancangan acak lengkap dengan enam ulangan. Data dianalisis menggunakan analisis sidik ragam dan uji lanjut dengan Uji Beda Nyata Terkecil (BNT). Hasil penelitian menunjukkan bahwa (1) pemberian bokashi di lahan persawahan Desa Montong Are dapat meningkatkan produksi terong ungu, (2) kadar optimum bokashi yang perlu diberikan pada lahan persawahan Desa Montong Are agar terong ungu berproduksi secara optimal adalah $1,2 \mathrm{~kg}$ untuk setiap $10 \mathrm{~kg}$ tanah.
\end{abstract}

Kata kunci: bokashi, produksi, terong ungu

\begin{abstract}
This research has done in Montong Are Village West Lombok. The objective of this research are: (1) to identify the effect of bokasi on the production of purple eggplant, (2) to identify the optimum extent of bokasi that must be added to the parm land in order that purple eggplant can product optimally. Complately randomized design with six replicates were used in this research. Data analysis with Anova and least significant different (LSD).The result of this research are: (1) the application of bokasi has significant effect on the production of purple eggplant, (2) the optimum extent of bokasi that must be given to the soil in order purple eggplant can product optimally is $1,2 \mathrm{~kg}$ bokasi/10 kg soil.
\end{abstract}

Key words: Bokasi, production, purple eggplant 


\section{PENDAHULUAN}

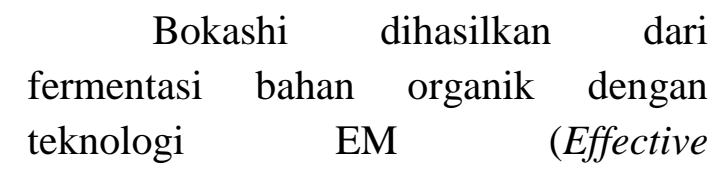

Microorganism), yang merupakan kultur campuran berbagai organisme yang bermanfaat sebagai pengurai bahan organik. Penggunaan Effective Microorganism dalam pembuatan bokashi selain memperbaiki kualitas tanah juga dapat meningkatkan produksi tanaman (Nasir. 2007). Bokashi adalah pupuk kompos yang dihasilkan dari proses fermentasi bahan organik dengan teknologi Effective Microorganism 4 (EM4). Effective Microorganism 4 mengandung Azotobacter sp., Lactobacillus sp., ragi, bakteri fotosintetik dan jamur pengurai selulosa (Teruo, 1999).

Berbagai hasil penelitian menunjukkan bahwa pemberian pupuk organik bokashi berpengaruh nyata terhadap jumlah anakan, tinggi tanaman, dan jumlah daun rumput gajah. Pemberian bokashi dosis 30 ton per hektar rata-rata memberikan pertumbuhan vegetatif terbaik dibandingkan dengan dosis yang lainnya (Kastalani dkk, 2017). Pemberian pupuk bokashi berpengaruh efektif terhadap pertumbuhan tanaman sawi (Nurzayyanah, 2009). Peberian bokashi kotoran sapi berpengaruh nyata terhadap tinggi tanaman rumput gajah mini (Zainudin, 2015). Pupuk bokashi kotoran kuda dan kotoran ayam berpengaruh terhadap panjang tanaman dan jumlah daun kancang panjang pada umur 24 hari setelah tanam dengan dosis yang terbaik adalah 20 ton per hektar (Djunaedy, 2009). Mengacu pada uraian di atas maka peneliti telah melakukan penelitian tentang pengaruh aplikasi bokashi terhadap produksi terong di Desa Montong Are Kabupaten Lombok Barat Propinsi Nusa Tenggara Barat. Adapun tujuan penelitian tersebut adalah untuk mengetahui (1) pengaruh aplikasi bokashi terhadap produksi terong pada lahan persawahan di Desa Montong Are, (2) dosis optimum bokashi yang perlu diberikan pada lahan persawahan Desa Montong Are agar tanaman terong dapat berprokduksi secara optimal

\section{BAHAN DAN METODE}

Bahan-bahan yang digunakan dalam penelitian ini adalah benih tanaman terong, tanah sawah Desa Montong Are, bambu dan kertas label. Selanjutnya alat-alat yang digunakan adalah cangkul, sekop, pot plastik, timbangan, parang, gunting alat tulis menulis dan ember plastik. Dalam penelitian ini digunakan rancangan acak lengkap dengan enam ulangan Penggunaan bokashi terdiri atas 6 level yaitu: $\mathrm{P}_{\mathrm{o}}=$ tanpa pemberian bokashi (kontrol), $\quad \mathrm{P}_{1}=$ pemberian $0,4 \mathrm{~kg}$ bokashi/10 kg tanah $\mathrm{P}_{2}=$ pemberian 0,8 $\mathrm{kg}$ bokashi $/ 10 \mathrm{~kg}$ tanah $\mathrm{P}_{3}=$ pemberian $1,2 \mathrm{~kg}$ bokashi/10 $\mathrm{kg}$ tanah $\mathrm{P}_{4}=$ pemberian $1,6 \mathrm{~kg}$ bokashi $/ 10 \mathrm{~kg}$ tanah $\mathrm{P}_{5}$ = pemberian $2,0 \mathrm{~kg}$ bokashi $/ 10 \mathrm{~kg}$ tanah (Hanafiah, 1994).

Parameter produksi yang diukur adalah berat basah buah terong ungu. Panen buah terong mulai dilakuakan setelah taman terong berumur 116 hari. 
Panen dilakukan sebanyak 5 kali dengan jarak waktu panen 5 hari. Data kuantitatif hasil pengukuran parameter di atas dianalisis dengan analisis sidik ragam dan uji lanjut dengan Uji Beda Nyata Terkecil (Gomez dan Gomez, 1995)

\section{HASIL DAN PEMBAHASAN}

Data rerata berat basah buah terong ungu pada setiap unit percobaan setelah dilakukan lima kali panen terdapat pada tabel berikut.

Tabel 1. Rerata berat basah buah terong ungu akibat aplikasi bokashi

\begin{tabular}{|c|c|}
\hline Perlakuan & $\begin{array}{c}\text { Rerata berat basah buah } \\
\text { (gr) }\end{array}$ \\
\hline $\mathrm{P}_{0}$ & 1826 \\
\hline $\mathrm{P}_{1}$ & 1984 \\
\hline $\mathrm{P}_{2}$ & 2216 \\
\hline $\mathrm{P}_{3}$ & 2482 \\
\hline $\mathrm{P}_{4}$ & 2486 \\
\hline $\mathrm{P}_{5}$ & 2476 \\
\hline
\end{tabular}

Hasil analisis sidik ragam pengaruh pemberian bokashi terhadap produksi terong ungu menunjukkan bahwa aplikasi bokashi berpengaruh nyata terhadap berat basah buah terong ungu. Tanaman terong ungu yang tumbuh pada media tanpa bokashi memiliki rerata berat basah buah 1826 gram. Selanjutnya pada setiap unit percobaan yang diberikan bokashi, rerata berat basah buah meningkat sejalan dengan meningkatnya kadar bokashi yang diberikan.. Hasil penelitian ini sejalan dengan hasil penelitian yang dilakukan oleh sejumlah peneliti. Pemberian bokashi berpengaruh nyata terhadap pertumbuhan dan produksi tomat pada lahan pertanian Desa Pijot (Raksun dan Santoso, 2010). Pemberian berbagai jenis bokashi memberikan pengaruh sangat nyata terhadap pertumbuhan dan hasil jagung manis, pemberian bokashi daun Johar memberikan hasil yang lebih baik terhadap pertumbuhan jagung manis, sedangkan pemberian bokashi daun Gamal memberikan hasil yang lebih baik terhadap produksi jagung manis (Mulyanti dkk, 2015).. Pemberian pupuk organik bokashi kotoran sapi dan eceng gondok dapat meningkatkan bobot berangkasan tanaman tomat (Soverda dkk, 2008). Terdapat interaksi antara pupuk organik bokashi dan pupuk nitrogen terhadap jumlah daun, pemberian pupuk organik bokashi 10 ton/ha berpengaruh baik terhadap komponen kualitas bunga yaitu mampu menghasilkan tangkai bunga terpanjang dan jumlah kuntum bunga terbanyak (Farida dan Hamdani, 2003), Pemupukan bokashi dengan dosis 20 ton per hektar memberikan bobot gabah kering per hektar tertinggi (4,70 ton), jumlah anakan produktif tertinggi $(25,00)$ dicapai varietas cianjur (Mulyana dkk, 2011). Pemberian pupuk bokashi Eceng Gondok menunjukkan respon sangat nyata pada total produksi kedelai per plot (Hasibuan dkk, 2017). Pemberian berbagai dosis pupuk organik bokashi berpengaruh nyata terhadap tinggi tanaman kedelai (Simaptupang, 1999). Pemberian pupuk kompos mampu meningkatkan pertumbuhan dan produksi padi di lahan pasang surut sulfat masam (Indriyati, 2005). Sejalan dengan hasil penelitian tersebut, Aliudin 
(2004) menyimpulkan bahwa penggunan pupuk kandang dan "fine compost" dapat meningkatkan hasil panen umbi kentang masing-masing sebesar $9,08 \%$ dan $16,25 \%$, serta meningkatkan jumlah umbi pertanaman masing-masing sebesar 20,87\% dan 19,24\%; Darma (2000) menyimpulkan bahwa kedelai varietas galunggung merespon secara signifikan terhadap kompos limbah kelapa sawit, produksi meningkat secara sigifikan. Raksun dan Alydrus (2004) menyimpulkan bahwa pemberian limbah kubis dapat meningkatkan pertumbuhan bawang merah di Desa Sajang Lombok Timur; Arijal dkk (2005) menyimpulkan bahwa penggunaan bokashi eceng gondok dapat meningkatkan produksi padi gogo dan kedelai; Jamal (2005), pemberian pupuk organik campuran pukan sapi, limbah ikan dan sludge dapat meningkatkan produksi kentang di Tapanuli Selatan. Aplikasi bokashi berpengaruh pada pertumbuhan vegetatif dan produksi rumput gajah. Bokashi 30 ton per hektar memberikan pertumbuhan vegetatif dan produksi rumput gajah tertinggi.Media terbaik untuk pertumbuhan semai eboni adalah pupuk organik EM bokashi karena media ini dapat meningkatkan solubilitas dan viabilitas hara dalam tanah dan memberikan pertumbuhan semai eboni yang optimal (Sumiasri dan Setyowati, 2006). Penambahan bokashi dalam dosis 250 g pada media tanah NPK dapat mendukung pertumbuhan cabe var. Inko 99 lebih optimal dengan tinggi tanaman $71,15 \mathrm{~cm}$ dan jumlah cabang produktif 40,75 buah (Gustia, 2009).
Berdasarkan hasil uji beda nyata terkecil diketahui bahwa, perlakuan $\mathrm{P}_{3}$ (perlakuan 1,2 kg bokashi/10 kg tanah) memberikan hasil yang berbeda nyata dengan $\mathrm{P}_{0}$ (kontrol), tetapi tidak berbeda nyata dengan perlakuan $\mathrm{P}_{4}$ dan $\mathrm{P}_{5}$. Hal ini menunjukkan bahwa dosis optimum bokashi yang perlu diberikan pada lahan persawahan Desa Montong Are adalah $1,2 \mathrm{~kg}$ bokashi per $10 \mathrm{~kg}$ tanah.

\section{KESIMPULAN}

Pada penelitian ini dapat disimpulkan bahwa: (1) aplikasi bokashi berpengaruh nyata terhadap produksi terong ungu, (2) penggunaan dosis bokashi $1,2 \mathrm{~kg}$ per $10 \mathrm{~kg}$ media tanah memberikan hasil yang lebih baik dibandingkan perlakuan lainnya.

\section{DAFTAR PUSTAKA}

Aliudin. 2004. Kajian Penggunaan Pupuk Organik "Fine Compost" Pada Hasil Panen Kentang Di Dataran Medium Propinsi Daerah Istimewa Yogyakarta. Abstrak Hasil Penelitian Pertanian Indonesia Pusat Perpustakaan dan Penyebaran Hasil Penelitian Indonesia. Vol. XI No.2. Bogor.

Arijal, Pabinru, A.M., dan Ibrahim B. 2005. Penggunaan Bokashi Eceng Gondok Pada Sistem Pertanian Tunggal dan Tumpangsari Padi Gogo dan Kedelai. Jurnal Sains \& Teknologi. Vol. 5 No. 1 27-36

Darma,S. 2000. Respon tanaman kedelai terhadap kompos limbah kelapa sawit pada dosis berbeda. 
Jurnal Budidaya Pertanian. 6 (2): $96-104$

Djunaedy, A. 2009. Pengaruh Dosis Pupuk Bokashi terhadap Pertumbuhan dan Hasil Kacang Panjang (Vigna sinensis L.). Agrivigor Vol 2(1): 42-46

Farida dan Hamdani, J.S. 2003. Pertumbuhan dan hasil bunga gladiol pada dosis pupuk organik bokashi dan nitrogen yang berbeda. Bionatura. 3(2): 68 - 76

Gomez K.A. dan A.A. Gomez. 1995. Prosedur Statistik Untuk Penelitian Pertanian Edisi Kedua Penerjemah: Endang Syamsudin dan Justika S. Baharsyah. UI Press. Jakarta.

Gustia, H. 2009. Pengaruh pemberian Bokashi Terhadap pertumbuhan dan produksi tanaman cabe var. inko-99. Akta Agrosia Vol. 12(2): $113-123$.

Hanafiah, K.A. 1994. Rancangan Percobaan. Teori dan Aplikasi. Fakultas Pertanian Universitas Sriwijaya. Palembang.

Hasibuan, S., Mawarni, R., Hendriandri, R. 2017. Respon Pemberian Pupuk Bokashi Ampas Tebu dan Pupuk Bokashi Eceng Gondok terhadap Pertumbuhan dan Produksi Tanaman Kedelai. Bernas 13(2): 59 - 64

Indrayati, L. 2005. Pengolahan Jerami Padi pada Pertanaman Padi Lahan Pasang Surut Sulfat Masam. Abstrak Hasil Penelitian Pertanian Indonesia Pusat Perpustakaan dan Penyebaran Hasil Penelitian Indonesia. Vol. XII No.2. Bogor.

Jamal, A. 2005. Penggunaan Pupuk Organik Untuk Pertumbuhan dan produksi Kentang di Tapanuli Selatan. Abstrak Hasil Penelitian
Pertanian Indonesia Pusat Perpustakaan dan Penyebaran Hasil Penelitian Indonesia. Vol. XII No.2. Bogor.

Kastalani, Kusuma, M.E. dan Melati, S. 2017. Pengaruh Pemberian Bokashi terhadap Pertumbuhan Vegetatif Rumput gajah (Pennisetum purpureum). Ziraa'ah. Vol 42 (2) 2017: 123127

Mulyana, D., Sahidin dan Iqbal, A. 2011. Pengaruh Dosis Bokashi terhadap Pertumbuhan dan Hasil Tiga Varietas Padi. Agrin 15(1): $18-26$

Mulyanti, S.S., Made, U. dan Wahyudi, I. Pengaruh Pemberian Berbagai Jenis Bokashi terhadap Pertumbuhan dan Hasil Jagung Manis (Zea mays Saccarata). Agrotekbis 3(5): 592 - 601

Nasir, 2007. Teknik Pembuatan Bokashi. http//www.dispeternakpandegela ng.go.id. Diakses tanggal 10 Februari 2009.

Nurzayyanah, 2009. Pengaruh Pemberian Pupuk Bokashi terhadap Pertumbuhan Tanaman Sawi (Brassica juncea L.). Skripsi. Fakultas Sains dan Teknologi Universitas Islam Negeri Maulana Malik Ibrahim Malang.

Raksun, A dan Alayrus, A 2004 Aplikasi Limbah Kubis Untuk Meningkatkan Pertumbuhan Bawang Merah Di Desa Sajang Kabupaten Lombok Timur. laporan Hasil Penelitian Universitas Mataram.

Raksun, A. dan Santoso D. 2010. Pemanfaatan Bokashi untuk Meningkatkan Pertumbuhan dan Produksi Tomat (Lycopersicum 
esculentum). Biologi Tropis 11 (1): $44-50$

Simatupang, Y.M.A. 1999. Pengaruh Pemberian Bokashi Kotoran Ayam dan Bokashi Rumput Terhadap Beberapa Sifat Fisika Tanah Podsolik Merah Kuning Gajrug dan Pertumbuhan Tanaman Kedelai (Glycine max L. Merr) varietas Wilis. Skripsi. Fakultas Pertanian Intitut Pertanian Bogor.

Soverda,N., Rinaldy dan I. Susanti. 2008. Pengaruh Beberapa Macam Bokashi Terhadap Pertumbuhan dan Hasil Tanaman Tomat (Lycopersicum esculentum Mill.) Di Polybag. journal.unja.id/index.php/agrono mi/article/download/432/348.
Diakses tanggal 1 Desember 2013.

Sumiarsi, N dan Setyowati, 2006. Pengaruh beberapa Media TerhadapPertumbuhan Bibit Eboni (Diospyros celebica Bakh). Melalui Perbanyakan biji . Biodipersitas. 7(3):260-263

Teruo, H. 1999. EM Technology. Indonesian Kyusei Nature Farming Societies. PT. Songgolangit Persada. Jakarta

Zainudin, A. 2015. Pengaruh Pemberian Bokashi Kotoran Sapi Terhadap Pertumbuhan dan Produksi Rumput Gajah Mini Pennisetum purpureum cv. Mott). Skripsi. Fakultas Peternakan Universitas Hasanudin Makasar. 